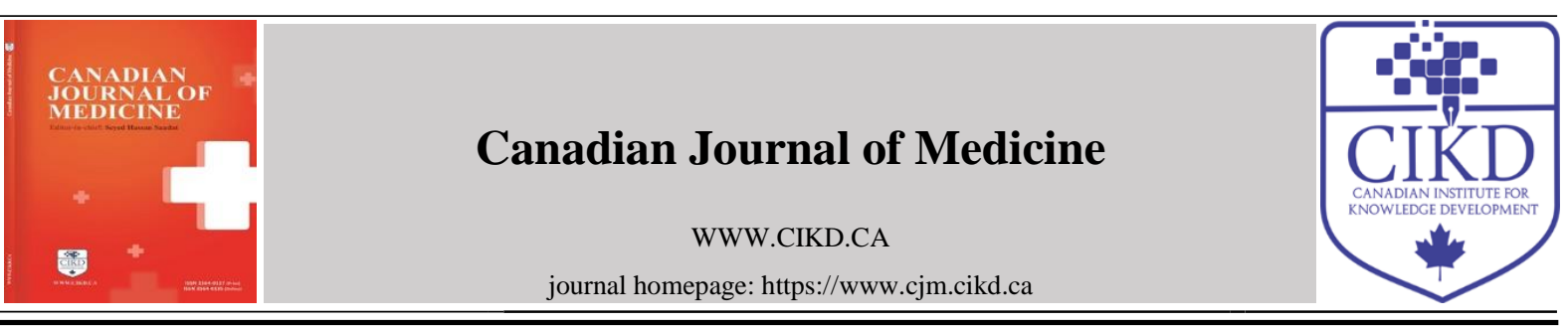

\title{
The Health of Companions: Evaluation of Care Burden, Psychological Distress and Psychiatric Disorders of the Companions of Patients in the Medical Ward of a University Hospital
}

\author{
Elif Duman Acar ${ }^{1}$, Melahat Akdeniz ${ }^{2 *}$, Ethem Kavukcu ${ }^{3}$, Esma Eseroglu ${ }^{4}$, \\ Hasan Hüseyin Avci ${ }^{5}$ \\ ${ }^{1,2,5}$ Department of Family Medicine, Faculty of Medicine, Akdeniz University, Antalya, Turkey \\ ${ }^{3}$ Department of Sport Medicine, Faculty of Medicine, Akdeniz University, Antalya, Turkey \\ ${ }^{4}$ Department of Internal Medicine, Faculty of Medicine, Akdeniz University, Antalya, Turkey
}

\section{Keywords: \\ Companion, Caregiver, Zarit Caregiver Burden Scale, Brief Symptom \\ Inventory, Hospitalized Patients}

\section{Received}

20 November 2021

Received in revised form

01 December 2021

Accepted

01 December 2021

*Correspondence:

melahatakdeniz@gmail.com

\begin{abstract}
The aim of this study was to evaluate the care burden, psychological distress, and psychiatric disorders of the companions of adult patients in the hospital. This study is a cross-sectional descriptive study. The study questionnaire included a sociodemographic information form, the Zarit Caregiver Burden Scale (ZCBS), and the Brief Symptom Inventory (BSI) were administered to the companions. Simple descriptive and inferential statistics were performed. The Mann-Whitney U test was used when there was no normal distribution. Correlation coefficients and statistical significance were calculated by using the Spearman test for at least one non-normal distributed relationship. A multiple linear regression analysis was performed for determining factors associated with BSI scores. The type 1 error level was used as $5 \%$ for statistical significance. All p-values of less than .05 were considered significant. Three hundred companions were included in the study. An emotional commitment was the leading cause of companionship. The mean values of the companions' ZCBS and BSI scores were 20.2 and 34.4, respectively. There was a moderately positive correlation $(\mathrm{r}=.50)$ between the ZCBS and BSI scores, and it was found to be statistically significant. ZCBS scores were positively associated with BSI scores. Psychological distress increases as the care burden of companions increases. Companions need more assistance from health care institutions, family members, and the community. The support of health workers and family members reduced the companions' care burden and psychological distress. Physicians working in the hospital should take into account that companions may be hidden patients.
\end{abstract}


The illness of a family member affects other family members, changes family relationships, and alters family life. If the disease is acute and curable, the effect on the family is minor and temporary. If serious, long-term chronic diseases and disabilities are present, problems arise in the care of the patient. To provide proper care for the sick family member at home or in the hospital environment, the roles within the family must be rearranged, and the routine lifestyle of the family changes $[1,2]$.

Family members play a major role in caring for a sick family member with a chronic illness. The physical, emotional, and economic difficulties experienced by the family members who provide care to the sick person adversely affect their quality of life. These difficulties faced by caregivers are called care burden [1,3].

George and Gwyther have defined caregiver burden as "the physical, psychological or emotional, social, and financial problems that can be experienced by family members caring for impaired older adults" [4]. "Zarit et al. also defined caregiver burden: "The extent to which caregivers perceive that caregiving has had an adverse effect on their emotional, social, financial, physical, and spiritual functioning" [5]. Although Caregiver burden is an important health problem, there is no International Classification of Diseases, Ninth Revision (ICD-9) or ICD-10 code for caregiver burden.

The family member exposed to care burden may experience physical, psychological, emotional, and functional health problems. In family-oriented primary care, these people are defined as "hidden patients" [2]. In any family with an individual with an acute and lifethreatening or chronic and long-term illness or diseases, the caregiver is under considerable stress. If this caregiver is not getting enough support from other family members, mechanisms for coping with stress may fail, and the caregiver may develop obvious or hidden signs of illness. For this reason, physicians need to evaluate the health status of caregivers as well as patients [2].

Most of the studies on care burden and quality of life of family members have been conducted on the problems and needs of people who provide home care for people with chronic diseases or who have limitations in daily life activities [6, 8].

Culturally, in some countries, such as Turkey, where there is a high tendency not to leave hospitalized family members alone, there is usually a family member who stays with the hospitalized patients, supporting and taking care of them. In Turkey, these people known as "refakatçi" (the patient's companion) could be spouses, children, close relatives, friends, or neighbors who provide important assistance to hospitalized persons. The companions assist the care of their relatives or friends in the fields of personal hygiene, nutrition, going to the toilet, bathing, and taking oral medication [9-13].

During the caregiving of the hospitalized patients, companions often find themselves isolated from society. They have very little time to maintain social contact with people. As companions spend considerable time in the hospital, their own care needs also arise. Furthermore, even if voluntarily performed, being detached from private life, having to leave an individual's home and workplace, and dealing with the severity of the disease of the patient who receives care creates a care burden on the companions. As a result, the companions are vulnerable to physical and psychological conditions and, their quality of life is negatively affected $[9,11]$. 
Currently, the number of studies examining hospital companions is very limited. Moreover, the health status of companions has not been investigated in these studies. Some of the existing studies on the caregivers of hospitalized relatives were conducted in Greece, where family members stay with patients for long periods and provide informal in-hospital care [13-17]. However, in these studies, informal caregivers' care burden and health status were not evaluated.

Bellou-Milona et al. [14] investigated health personnel's attitudes towards the participation of family members in patient care, health education, the need for information, and emotional support of companions. Stavrianou et al. [13] investigated the role of informal caregivers during the hospitalization of a family member, factors affecting their presence, and patient's needs. Sapountzi-Krepia et al. [16, 17], in 2 separate studies, investigated the kind and frequency of care provided to hospitalized cancer patients by relatives and the reasons for providing this care, as well as the type and frequency of caregiving activities provided by family members in the rehabilitation setting. Lavdaniti et al. [15] compared the perceptions of the nurses and the in hospital informal caregivers about patient care.

A study conducted by Rothman et al. [18] investigated how nurses, patients, and family members evaluated the participation of family members in the care of the patient. Islam et al. [19] examined whether companions were at risk for hospital-acquired resistant infections was investigated on companions in a tertiary hospital in Pakistan. A study conducted by Sadigh et al. [20] in Uganda, investigated companions' demographic data, difficulties faced, and the effects of these difficulties on patient care; however, their health status and care burden were not investigated. In Brazil, a qualitative study conducted by Passos et al. [12] investigated the changes in the routine of the family companion during the hospitalization of a family member.

There are studies related to companions in Turkey. A study by Sarıtaş et al. [21] investigated the burden of care for the companions of patients hospitalized in the oncology service. Akpinar et al. [9] identified and described the concept of the patients' companions from the perspectives of the companions and evaluated the concept of the patient's companion in terms of biomedical ethics. Celik et al. [22] investigated the roles, expectations, and problems of patient companions.

In the mentioned studies, however, the health status of the companions was not evaluated, which may have a significant effect on the care burden. It is known that the care burden on the caregiver affects their physical, mental, and social health, and cultural characteristics will change the caregiver/companion's perception of care burden [7, 9].

In Turkey, there is a companion present for the majority of hospitalized adult and pediatric patients. Awareness of the companion's care burden and the possible effects of this burden on their health can be a guide to protecting and improving their health. Hence, in this study, we aimed to evaluate the care burden, psychological distress, and psychiatric disorders of companions of adult patients who were hospitalized in the medical ward of Akdeniz University Hospital.

\section{Materials and Methods}

This study is a cross-sectional and descriptive study. The study sample comprised companions of inpatients admitted to the university hospital between January and April 2018. Companions who were over 18 years old and were involved in caring for the patient for at least five 
continuous days in the hospital were included in the study. In hospitals of Turkey, companions are not the same persons for hospitalizations of less than five days. In hospitalizations longer than five days, the same person stays with the patient as a companion. Therefore, we took five days as a starting point. This study is originated from one center, and sample calculation and randomization were not performed based on the suggestions of the statisticians. Since the number of companions of inpatients could not be known clearly during the research, expert statisticians suggested that there should be at least 250 participants. Therefore, we recruited 300 companions who agreed to participate in the study.

The inclusion criteria in the study were older than 18 years of age, giving care to an adult patient in the hospital as a companion for more than five days, and giving informed consent to participate in the study. The exclusion criteria were being younger than 18 years of age, giving care as a companion for less than five consecutive days, not giving informed consent to participate in the study, and being a paid caregiver.

The Akdeniz University, Faculty of Medicine Clinical Research Ethics Committee dated 20 December 2017 and numbered 747 approved the scientific and ethical relevance of this study. Written informed consent was obtained from all companions who agreed to participate in the study. Then, the study questionnaire, which included sociodemographic data, the Zarit Caregiver Burden Scale, and the Brief Symptom Inventory, were administered by the researchers in face-to-face interviews. A sociodemographic information form is a 33-item form that includes age, sex, educational level, income level, history of chronic illness, degree of intimacy, duration of companionship, problems encountered during the hospital stay, and cause of companionship.

The Zarit Caregiver Burden Scale (ZCBS) is widely accepted as a reliable and valid scale for measuring caregivers' burden and has been used extensively. It was developed in 1980 by Zarit, Reever, and Bach-Peterson [5]. Inci and Erdem conducted Turkish validity studies in 2006 [23]. The ZCBS, which may be filled out either by the caregiver or a researcher, consists of 22 statements on the effect of caregiving on the respondent's/caregiver's life. Each of the statements is answered using a Likert-type scale, with scores ranging from 0 to 4 (never, rarely, sometimes, quite frequently, and nearly always). The composite score was then calculated, and the burden was graded as follows: little or no burden $(\leq 20)$, mild burden $(21-40)$, moderate to severe burden (41-60), and severe burden (>61-88). The ZCBS has good internal consistency reliability, with a Cronbach's alpha coefficient of .92.

The Brief Symptom Inventory (BSI) is an instrument that evaluates psychological distress and psychiatric disorders in people. Derogatis developed it in 1975 [24]. The BSI is a 53-item self-report scale designed to evaluate psychopathological and psychological symptoms, measuring nine dimensions (somatization, obsession-compulsion, interpersonal sensitivity, depression, anxiety, hostility, phobic anxiety, paranoid ideation, and psychoticism). Respondents rank each feeling item (e.g., your feelings being easily hurt) on a 5-point scale ranging from 0 (not at all) to 4 (extremely). The rankings characterize the intensity of distress during the past seven days. The total score from the scale varies between 0 and 212 .

The Turkish version used in this study was adapted to Turkish by Sahin and Durak [25]. In the Turkish version, five dimensions are defined.

1. Anxiety (13 items): Feeling nervous and irritated

2. Depression (12 items): Feelings of despair about the future 
3. Negative self-size (12 items): Feelings of guilt

4. Somatization ( 9 items): Faintness, dizziness

5. Hostility (7 items): Breaking something, cast request

The data obtained were analyzed using IBM SPSS Packet version 24.0 (IBM Corporation, Armonk, NY, USA). While evaluating the data, the suitability of the parameters to a normal distribution was evaluated by visual (histogram and probability graphs) and analytical methods (Kolmogrov-Smirnov / Shapiro Wilk tests). Simple descriptive and inferential statistics were performed. Descriptive statistics were performed with results presented as frequencies, proportions, means, and standard deviations. The Mann-Whitney U test was used when there was no normal distrubition. If the groups with more than two independent groups did not show a normal distribution, these parameters such as education level, monthly income, self-rated health, and mental illnesses of companions were compared using the Kruskal-Wallis test. Pairwise comparisons were made using the Mann-Whitney $U$ test and evaluated using Bonferroni correction. Correlation coefficients and statistical significance were calculated by using the Spearman test for at least one normal non-distributed relationship. The type 1 error level was used as $5 \%$ for statistical significance. All $p$-values of less than .05 were considered significant.

The hypothesis of this study is that psychological distress and psychiatric disorders of companions also increase as the care burden of companions of adult patients increases.

\section{Results}

Three hundred companions participated in the study, comprising 99 (33\%) males and 201 (67\%) females, with ages ranging from 18 to 84 years (mean $=50$ years). Half of the participants live in the city center, $37.7 \%$ were primary school graduates, and $37.7 \%$ were low-income.

\section{Table 1}

The Socio-Demographic Profile of Companions $(N=300)$

\begin{tabular}{|c|c|c|}
\hline & Number (n) & Percent (\%) * \\
\hline \multicolumn{3}{|l|}{ Sex } \\
\hline Male & 99 & 33,0 \\
\hline Female & 201 & 67,0 \\
\hline \multicolumn{3}{|l|}{ Education level } \\
\hline Literate & 16 & 5,3 \\
\hline Primary school graduate & 113 & 37,7 \\
\hline Secondary school graduate & 42 & 14,0 \\
\hline High school graduate & 65 & 21,7 \\
\hline Graduate & 21 & 7,0 \\
\hline Graduated from a University & 43 & 14,3 \\
\hline \multicolumn{3}{|l|}{ Place of Residence } \\
\hline City center & 157 & 52,3 \\
\hline District & 112 & 37,3 \\
\hline Village & 31 & 10,3 \\
\hline \multicolumn{3}{|l|}{ Monthly Income } \\
\hline Low: $0-300 \$$ & 112 & 37,7 \\
\hline Medium: $301-2000 \$$ & 155 & 52,2 \\
\hline High: 2001 \$ and above & 30 & 10,1 \\
\hline * Column percentage & & \\
\hline
\end{tabular}

In the study, $35.7 \%$ of companions considered their health to be fair or poor, only $2.7 \%$ considered their health to be excellent. About half of the companions (45.5\%) had at least one chronic disease, and the most frequently reported chronic disease was hypertension $(27.3 \%)$. Twenty-four percent of the companions reported having had a previous mental illness. The most common mental illness was depression (17.6\%). 
Table 2

The Health Characteristics Reported by the Companions themselves

\begin{tabular}{lll}
\hline Self-rated health (n=300) & Number (n) & Percent (\%)* \\
Exellent & 8 & 2.7 \\
Very good & 25 & 8.4 \\
Good & 159 & 53.2 \\
Fair & 100 & 33.4 \\
Poor & 7 & 2.3 \\
Yes & & 45.5 \\
No & 137 & 54.5 \\
Do you have chronic disease? (n=300) & 163 & 27.3 \\
Hypertension & & 20.1 \\
Diabetes mellitus & 53 & 15.9 \\
Cardiovascular diseases & 39 & 7.7 \\
Hypothyroidism & 31 & 4.6 \\
Asthma & 15 & 4.6 \\
Neurological diseases & 9 & 4.1 \\
Gastrointestinal disease & 9 & 3.0 \\
Hyperlipidemia & 8 & 2.0 \\
Osteoporosis & 6 & 10.3 \\
Other & 4 & 74.6 \\
Depression & 24 & 16.9 \\
Anxiety Disorder & & 1.4 \\
Obsessive compulsive disorder & & 7.1 \\
Other & 53 & \\
Previous & & \\
\hline peral illnesses (n=71) & 12 & \\
\hline
\end{tabular}

* Column percentage

\# Multiple options checked

Forty-one percent of the companions were spouses of the patients, and $42.8 \%$ had been caring for their patients in the hospital for more than two weeks. In the study, $61.3 \%$ of the participants were not working professionally, and 30\% had trouble getting permission from their job. Seventy-seven percent of the respondents reported caring for the patient because of their emotional commitment. Approximately one-third of the companions did not receive support from the family, and $35.9 \%$ reported that they had problems meeting their basic needs during the hospital stay. 
Table 3

Some Characteristics of Companions $(N=300)$

\begin{tabular}{|c|c|c|}
\hline & Number (n) & Percent $(\%)^{*}$ \\
\hline \multicolumn{3}{|l|}{ Proximity/relationship with the person to whom care of companion } \\
\hline Spouse & 124 & 41.3 \\
\hline Children & 109 & 36.3 \\
\hline Sibling & 14 & 4.7 \\
\hline One of other relatives & 50 & 16.7 \\
\hline Friend & 3 & 1.0 \\
\hline \multicolumn{3}{|l|}{ Duration of companionship in the hospital } \\
\hline Less than 1 week (5-7 days) & 96 & 32.1 \\
\hline $1-2$ weeks (8-14 day) & 75 & 25.1 \\
\hline More than 2 weeks (15 days and more) & 128 & 42.8 \\
\hline \multicolumn{3}{|l|}{ Does the companion care for this patient outside the hospital? } \\
\hline Yes & 140 & 46.7 \\
\hline No & 100 & 33.3 \\
\hline Sometimes & 60 & 20.0 \\
\hline \multicolumn{3}{|l|}{ Has the companion had previously worked in an income-generating business? } \\
\hline Yes & 116 & 38.7 \\
\hline No & 184 & 61.3 \\
\hline \multicolumn{3}{|l|}{ Has the companion had trouble getting permission from his job? $(n=116)$} \\
\hline Yes & 34 & 29.3 \\
\hline No & 82 & 70.7 \\
\hline \multicolumn{3}{|l|}{ What does the companion help the patient during accompany? \# } \\
\hline Feeding & 102 & 34.0 \\
\hline Giving your medicine & 153 & 51.0 \\
\hline Measuring your temperature & 109 & 36.3 \\
\hline Take to the toilet / bathroom & 181 & 60.3 \\
\hline Helping your physiotherapist & 25 & 8.3 \\
\hline Taking to imaging examinations to be performed in other sections & 102 & 34.0 \\
\hline \multicolumn{3}{|l|}{ Reason of caregiving for patient \# } \\
\hline Sense of duty & 29 & 9.6 \\
\hline No other alternative & 12 & 4.0 \\
\hline High cost of professional caregiver & 5 & 1.6 \\
\hline Emotional (love. commitment) & 231 & 77.0 \\
\hline Patient preference & 20 & 6.6 \\
\hline Religionial belief & 29 & 9.6 \\
\hline Feeling responsibility fot the patient as a family member & 120 & 40.0 \\
\hline
\end{tabular}

* Column percentage

\# Multiple answers were given to these questions.

The companions' care burden was calculated using the ZCBS. The companions' mean ZCBS scores were 20.2 \pm 13.1 . More than half of the companions (55\%) had a little care burden, about $8 \%$ had a moderate to severe care burden. Psychological distress and psychiatric disorders in the companions were calculated using BSI. The mean BSI score of the participants was 34.4.

Table 4

The Distribution of ZBI Scores and BSI Scores of the Participants $(N=300)$

\begin{tabular}{|c|c|c|}
\hline & Mean \pm SD & Median (Min-Mak) \\
\hline ZBI total score (min $0, \max 88$ puan) & $20.2 \pm 13.1$ & $17(.0-63)$ \\
\hline Classification by ZBI total score & Number (n) & Percent $(\%)$ \\
\hline Little or no burden $(\min 0, \max 20)$ & 175 & 58.3 \\
\hline Mild burden $(\min 21$, maxks 40$)$ & 101 & 33.6 \\
\hline Moderate to severe burden $(\min 41, \max 60)$ & 22 & 7.3 \\
\hline \multirow[t]{2}{*}{ Severe burden $(\min 61, \max 88)$} & 2 & 0.6 \\
\hline & Mean \pm SD & Median (Min-Mak) \\
\hline BSI total score (Min:0) (Max; 212) & $34.4 \pm 27.6$ & $28(.0-205)$ \\
\hline BSI subscale's scores (min-max) & Mean \pm SD & Median (Min-Mak) \\
\hline Depression $(0-60)$ & $11.1 \pm 9.2$ & $9(.0-48)$ \\
\hline Anxiety $(0-65)$ & $6.7 \pm 7.1$ & $5(.0-52)$ \\
\hline Negative self-size $(0-60)$ & $6.4 \pm 6.0$ & $5(.0-48)$ \\
\hline Somatization $(0-45)$ & $5.6 \pm 5.1$ & $4(.0-29)$ \\
\hline Hostility $(0-35)$ & $4.3 \pm 3.8$ & $3.5(.0-28)$ \\
\hline
\end{tabular}


There was a moderate positive correlation $(r=.50)$ between the ZCBS and BSI scores of the participants, and it was statistically significant $(p<.05)$. This, as expected, indicates that healthrelated complaints increase with an increased care burden. There was no statistically significant difference between the sexes, income levels, self-rated health and chronic disease status of the companions, and the ZCBS scores $(p>.05)$. The ZCBS score was found to be significantly higher in companions with a previous history of mental illness than in those without $(p<.05)$; however, there was no statistically significant difference between the type of mental illness and the ZCBS scores $(p>.05)$.

The relationship of a patient receiving care from a companion, the duration of the companionship, the state of caregiving outside the hospital, having trouble meeting their basic needs in the hospital, the status of working a job, and the status of the problem of getting permission from work had a statistically significant effect on the care burden $(p<.05)$.

Table 5

ZCBS Score Distribution According to the Characteristics of Companions

\begin{tabular}{|c|c|c|c|c|}
\hline & & Mean \pm SD & Median (Min-Max) & $p$ \\
\hline \multirow{2}{*}{ Sex } & Male & $19.9 \pm 13.1$ & $16(.0-59)$ & \multirow{2}{*}{$.391 *$} \\
\hline & Female & $20.9 \pm 13.1$ & $19(1-63)$ & \\
\hline \multirow[t]{3}{*}{ Monthly Income } & Low: $\leq 300 \$$ & $19.4 \pm 12.4$ & $16(1-57)$ & \multirow{3}{*}{$.691 * *$} \\
\hline & Medium: $301-2000 \$$ & $20.7 \pm 13.4$ & $17(.0-63)$ & \\
\hline & High: $\geq 2001 \$$ & $19.9 \pm 14.4$ & $16(3-62)$ & \\
\hline \multirow{5}{*}{$\begin{array}{l}\text { Relationship of patient } \\
\text { receiving care with the } \\
\text { companion }\end{array}$} & Spouse & $19.4 \pm 12.4$ & $16(.0-59)$ & \multirow{5}{*}{$.029 * *$} \\
\hline & Children & $22.4 \pm 13.4$ & $21(.0-63)$ & \\
\hline & Sibling & $19.6 \pm 14.2$ & $15.5(3-50)$ & \\
\hline & One of other relatives & $18.3 \pm 13.6$ & $14(2-57)$ & \\
\hline & Friend & $7.0 \pm 1.7$ & $8(5-8)$ & \\
\hline \multirow{5}{*}{ Self-rated health } & Exellent & $15.4 \pm 13.4$ & $12.5(3-44)$ & \multirow{5}{*}{$.353 * *$} \\
\hline & Very good & $25.5 \pm 17.0$ & $23(2-63)$ & \\
\hline & Good & $19.7 \pm 12.1$ & $16(.0-57)$ & \\
\hline & Fair & $19.7 \pm 12.5$ & $17(1-57)$ & \\
\hline & Poor & $27.5 \pm 22.3$ & $36(3-59)$ & \\
\hline \multirow{3}{*}{ Duration of caregiving } & Less than 1 week & $17.8 \pm 12.8$ & $15.5(1-63)$ & \multirow{3}{*}{$.036^{* *}$} \\
\hline & $1-2$ weeks & $20.3 \pm 13.3$ & $17(3-56)$ & \\
\hline & $>2$ weeks & $21.9 \pm 13.1$ & $20(.0-62)$ & \\
\hline \multirow{3}{*}{$\begin{array}{l}\text { State of caregiving outside } \\
\text { the hospital }\end{array}$} & Yes & $24.2 \pm 14.2$ & $21.5(.0-63)$ & \multirow{3}{*}{$<.001 * *$} \\
\hline & No & $15.8 \pm 10.3$ & $14(1-47)$ & \\
\hline & Sometimes & $18.2 \pm 11.9$ & $15(.0-55)$ & \\
\hline \multirow{2}{*}{ Status of working in a job } & Yes & $22.4 \pm 13.6$ & $21(.0-62)$ & \multirow{2}{*}{$.018 *$} \\
\hline & No & $18.8 \pm 12.6$ & $16(.0-63)$ & \\
\hline \multirow{2}{*}{$\begin{array}{l}\text { Status of the problem of } \\
\text { getting permission from } \\
\text { work }\end{array}$} & Yes & $27.7 \pm 13.8$ & $29(5-62)$ & \multirow[b]{2}{*}{$.005^{*}$} \\
\hline & No & $20.3 \pm 13.1$ & $17(.0-63)$ & \\
\hline \multirow{2}{*}{$\begin{array}{l}\text { Having trouble meeting their } \\
\text { basic needs in the hospital }\end{array}$} & Yes & $22.1 \pm 12.3$ & $21(.0-55)$ & \multirow[t]{2}{*}{$.008^{*}$} \\
\hline & No & $19.1 \pm 13.5$ & $15(.0-63)$ & \\
\hline \multirow{2}{*}{$\begin{array}{l}\text { Previous history of mental } \\
\text { illness }\end{array}$} & Yes & $23.5 \pm 12.8$ & $21.5(4-55)$ & \multirow{2}{*}{$.007 *$} \\
\hline & No & $19.2 \pm 13.1$ & $16(.0-63)$ & \\
\hline \multirow{3}{*}{ Mental illnesses $(\mathrm{n}=71)^{* *}$} & Depression & $57.9 \pm 36.8$ & $53(6-205)$ & \multirow{3}{*}{$.06^{* *}$} \\
\hline & Anxiety Disorder & $30.7 \pm 16.2$ & $25(14-66)$ & \\
\hline & Obsessive compulsive disorder & $51.0 \pm 0.0$ & $51(51-51)$ & \\
\hline \multirow{2}{*}{$\begin{array}{l}\text { Receiving support from } \\
\text { other family members }\end{array}$} & Yes & $17.7 \pm 12.0$ & $15.5(.0-63)$ & \multirow[t]{2}{*}{$.0001 *$} \\
\hline & No & $25.7 \pm 13.8$ & $25(.0-62)$ & \\
\hline
\end{tabular}

* Mann- Whitney U Test; **Kruskall- Wallis Test

The care burden of companions who did not receive support from other family members was significantly higher than those receiving support $(25.7$ vs 17.7$)(p<.0001)$. The difficulty in meeting the basic needs of companions such as bathing, eating, and sleeping during the hospital stay increased the care burden as expected $(p<.05)$. 
There was a statistically significant difference between the BSI scores according to sex, general health perception (self-rated health), state of caregiving outside the hospital, experiencing difficulties in meeting their basic needs in the hospital, and the previous history of mental illnesses of the companions $(p<.05)$.

There was no statistically significant difference between the BSI scores according to education levels, income levels, duration of companionship, and having any diagnosed chronic disease of the companions $(p>.05)$.

Table 6

The Distribution of BSI Scores according to Some Descriptive Characteristics of Companions

\begin{tabular}{|c|c|c|c|c|}
\hline & & Mean \pm SD & Median (Min-Max) & $p$ \\
\hline \multirow{2}{*}{ Sex } & Male & $27.1 \pm 25.0$ & $21(.0-145)$ & \multirow[b]{2}{*}{$<.001 *$} \\
\hline & Female & $38.0 \pm 28.2$ & $31(.0-205)$ & \\
\hline \multirow{6}{*}{ Education level } & Literate & $34.6 \pm 20.3$ & $32.5(5-65)$ & \multirow{6}{*}{$.920 * *$} \\
\hline & Primary school graduate & $33.9 \pm 23.9$ & $30(.0-105)$ & \\
\hline & Secondary school graduate & $35.0 \pm 29.8$ & $26.5(.0-124)$ & \\
\hline & High school graduate & $37.5 \pm 34.7$ & $27(.0-205)$ & \\
\hline & Graduate & $28.1 \pm 18.9$ & $26.0(.0-80)$ & \\
\hline & Graduated from a University & $33.5 \pm 29.2$ & $25(2-145)$ & \\
\hline \multirow{3}{*}{ Monthly Income } & Low: $0-300 \$$ & $34.8 \pm 28.3$ & $28(.0-126)$ & \multirow{3}{*}{$.205^{* *}$} \\
\hline & Medium: $301-2000 \$$ & $20.7 \pm 13.4$ & $30(.0-124)$ & \\
\hline & High: $2001 \$$ and above & $19.9 \pm 14.4$ & $22(4-145)$ & \\
\hline \multirow{5}{*}{ Self-rated health } & Excellent & $15.2 \pm 13.2$ & $10.5(.0-35)$ & \multirow{5}{*}{$<.001^{* *}$} \\
\hline & Very good & $28.5 \pm 18.2$ & $25(.0-67)$ & \\
\hline & Good & $31.2 \pm 27.9$ & $25(.0-205)$ & \\
\hline & Fair & $41.6 \pm 28.1$ & $36(.0-145)$ & \\
\hline & Poor & $51.1 \pm 28.3$ & $58(10-81)$ & \\
\hline \multirow{3}{*}{ Duration of caregiving } & Less than 1 week & $32.4 \pm 25.2$ & $26(.0-113)$ & \multirow{3}{*}{$.633^{* *}$} \\
\hline & $1-2$ weeks & $34.7 \pm 24.5$ & $31(.0-124)$ & \\
\hline & More than 2 weeks & $35.7 \pm 31.1$ & $28(.0-205)$ & \\
\hline \multirow{3}{*}{$\begin{array}{l}\text { State of caregiving } \\
\text { outside the hospital }\end{array}$} & Yes & $39.1 \pm 30.4$ & $32(.0-205)$ & \multirow{3}{*}{$.016^{* *}$} \\
\hline & No & $27.6 \pm 19.9$ & $25(.0-87)$ & \\
\hline & Sometimes & $34.9 \pm 29.8$ & $28.5(.0-145)$ & \\
\hline \multirow{2}{*}{$\begin{array}{l}\text { Having trouble meeting } \\
\text { their basic needs in the } \\
\text { hospital }\end{array}$} & Yes & $43.9 \pm 33.7$ & $35(.0-205)$ & \multirow[b]{2}{*}{.0001} \\
\hline & No & $28.9 \pm 21.8$ & $25(.0-105)$ & \\
\hline \multirow{2}{*}{$\begin{array}{l}\text { Do you have chronic } \\
\text { disease? }\end{array}$} & Yes & $34.7 \pm 23.9$ & $29.5(.0-110)$ & \multirow{2}{*}{$.333^{*}$} \\
\hline & No & $34.3 \pm 30.2$ & $27(.0-205)$ & \\
\hline \multirow{2}{*}{$\begin{array}{l}\text { Previous history of mental } \\
\text { illness }\end{array}$} & Yes & $52.8 \pm 35.2$ & $48(6-205.09$ & \multirow{2}{*}{$<.001 *$} \\
\hline & No & $29.2 \pm 22.6$ & $25(.0-124)$ & \\
\hline \multirow{3}{*}{ Mental illnesses $(\mathrm{n}=71)^{* *}$} & Depression & $57.9 \pm 36.8$ & $53(6-205)$ & \multirow{3}{*}{$.013^{* *}$} \\
\hline & Anxiety Disorder & $30.7 \pm 16.2$ & $25(14-66)$ & \\
\hline & Obsessive compulsive disorder & $51.0 \pm 0.0$ & $51(51-51)$ & \\
\hline \multirow{2}{*}{$\begin{array}{l}\text { Receiving support from } \\
\text { other family members }\end{array}$} & Yes & $31.8 \pm 24.1$ & $40.8 \pm 33.3$ & \multirow[t]{2}{*}{$.054^{*}$} \\
\hline & No & $28.0(0.0-145.0)$ & $31(.0-205)$ & \\
\hline
\end{tabular}

* Mann- Whitney U Testi; ** Kruskall- Wallis Testi

There was no statistically significant difference between the BSI scores and the degree of the relationship between the companion and the patient or the length of hospital care $(p>.05)$. Certain tasks, such as giving the patient their medication, measuring the patient's body temperature, and helping the patient go to the bathroom and the toilet, created more care burden for the companions and led to higher BSI scores. Lack of support from the environment and the family members of the companions significantly increased the score of the hostility subgroup $(p<.013)$. The difference between the other subgroups was not statistically significant.

When evaluating the reason for being a companion, the highest BSI score was from "I give care because of the high cost of professional care" (58.4\%). This was followed by the absence of choice $(47.5 \%)$ and feeling of duty (37.7\%). However, contrary to the ZCBS scores, there 
was no statistically significant relationship between the reason for being a companion and the BSI scores $(p>.05)$.

As expected, companions who have problems meeting basic needs during the hospital stay have higher BSI scores than those who do not, and this difference was statistically significant $(\mathrm{p}<.05)$.

\section{Discussion}

Family members play a major role in caring for sick family members who have chronic illnesses. Family members who are caring for the sick person face the care burden and may experience physical and mental health problems as a result of their care responsibilities. In Turkey, a family member remains in the hospital as a companion to the hospitalized patient and takes responsibility for the care of the patient.

As stated in the method section, a sample calculation could not be made in this study because of difficulties predicting the total number of companions. We recruited 300 companions who agreed to participate in the study. Two-thirds of the companions were women.

In almost every country in the world, women are the main caregivers for the sick, the elderly, the disabled, and the young. Caring for the sick person in the family is accepted as the responsibility of women. Historically, women are responsible for the care of the home, children, and the care in case of illness of a family member. Women accept their caregiver role as a cultural obligation [26]. Patient care at home and in the hospital is considered the natural task of women [9]. Today, although women increasingly participate in business life, the majority of family caregivers are female members of the family [1,11]. The U.S. Family Caregiver Alliance reports that upwards of $75 \%$ of all caregivers are female [27]. In a study by Chandran et al. [28] in India, $70 \%$ of family members who care for hospitalized patients are women. In a qualitative study by Passos et al. [12] in Brazil, $81 \%$ of family caregivers who care for hospitalized patients are women.

In the present study, companions' care burden was evaluated with the ZCBS. The mean ZBI score was 20.2 / 88. This score corresponds to little burden. Studies on the care burden are more concerned with the care burden of home caregivers. There are few studies on the care burden of the companions of hospitalized patients. In Turkey, Saritas et al. [21] conducted a study with the caregivers of patients at the oncology service. The mean ZCBS score of the caregivers was found to be 25. This higher score may be due to the high burden of care for oncology patients. Chandran et al. [28] conducted a study in India, and the average ZCBS score of the caregivers for the patients in a private room was 45.4; the ZCBS score of the caregivers for the patients in general room was 35.4. The difference between the results of this study and our results might be due to cultural beliefs and habits between the two communities and the conditions of the hospitals. In Turkish culture, providing care to a close relative is considered an honor and is performed voluntarily, whereas in Indian society, caring for hospitalized relatives is considered a cultural and religious duty [11]. In this study, the care burden did not increase in companions whose motivations are emotional ties (love, feeling close) with the patient and religious beliefs $(p<.05)$. In contrast, the care burden of companions, who felt that they must be a companion because of a sense of duty, the cost of professional help, feeling responsible as a family member and a lack of other options, were significantly higher. In the study, $77 \%$ of the companions stated that they were accompanying persons for emotional reasons. 
A meta-analysis of 125 studies by Rodriguez-Gonzales and Rodríguez-Míguez [29] showed that caregivers of individuals with a physical disability have an estimated mean ZCBS score of 27. The lower score in this study might be due to the shorter duration of care in the hospital and the potential for recovery in the patients who receive care.

In this study, ZCBS scores did not show statistically significant differences according to the sex, education levels, income levels, general health perception of the companions $(p>.05)$. However, as the length of the caregiving time increased, the care burden also increased $(p<$ .05). In addition, working in an income-generating work and having problems obtaining work permits to become a companion increased the care burden. In a study by Saritas et al. [21], a statistically significant relationship between sex and educational status with care burden was not found. These findings are in accordance with our conclusions.

Companions are usually relatives of patients, and they play a significant role in supporting their patients emotionally. In this study, most of the companions were spouses or adult children of the patients. The companions' relationship with the patient receiving care affects the care burden. In this study, the highest care burden (22.4/88) was found in the adult children of the patients. This is followed by spouses and siblings (19.4/88 in both). This might be due to the separation of young persons from social life or business life, creating more stress.

More than half of the companions considered their health to be good, and $45.5 \%$ had at least one chronic disease. This is likely to be due to the average age of the companions, which was 50 years old. In Turkey, the prevalence of multimorbidity in the population aged 40 and over is $27.8 \%$ and increases with age [30].

Companions who stay with their patients in the hospital live in uncomfortable conditions. As this period is prolonged, they experience physical and mental problems. It was previously documented that the companions have unsatisfactory physical conditions such as a lack of resting and sleeping places in Turkey $[9,22]$. As stated in the results section of our study, the difficulty in meeting the basic needs of companions such as bathing, eating, resting, and sleeping during the hospital stay increased the care burden.

In the study, BSI was used to evaluate the psychological distress of the companions. Female companions had higher BSI scores than male companions $(p<.05)$. In a few studies that investigated the relationship between the caregiver's sex and quality of life, it was reported that women were more likely to be depressed [12, 31]. In general, women spend more time at home than men and support their children's care and education. Therefore, it is likely that anxiety of the women increases because of separation from their homes and children.

According to the research, there is a strong link between psychological health and physical health [32]. As expected, there was an inverse linear relationship between the companion's selfrated health status with their BSI scores. While the BSI score of those who evaluated their health as excellent was the lowest, those with poor health were found to have the highest BSI scores. BSI scores of the companions with a previous history of mental illness were also statistically significantly higher. However, there is no statistical difference between the BSI scores when comparing companions with chronic illnesses and those without chronic illnesses. These results show us that the healthiness perception of the companions is related to mental health rather than physical health. The absence of a significant relationship between the ZCBS score with the companion's health self-assessment and chronic illness reinforces this assumption. 
There was no statistically significant difference between the BSI scores regarding the degree of closeness between the companion and the family member receiving care and the duration of companionship at the hospital $(p>.05)$. However, the BSI scores of the companions who provided care to the same person outside the hospital were significantly higher $(p<.05)$. This result shows that the longer the period of companionship, the more likely it is to affect the mental and physical health of the companion.

These results show that the length of the caregiving duration and the poor health perception negatively affect the mental health of the companion, regardless of the care burden. Although the care burden of the companions was not significantly affected by current health perceptions or existing chronic diseases, the increased level of psychological symptoms may stem from the fact that the companion prioritizes the health and care of the patient rather than to their own health. In addition, stress or sadness during the care process may also increase psychological symptoms. Further studies are needed to determine the main factors.

In this study, half of the companions stated that they also provide care to their patients outside the hospital. These people have higher ZBI scores and BSI scores than companions just providing care in the hospital. These companions may also be considered home caregivers and may have the same health risks as home caregivers. For this reason, we think that studies on long-term caregivers of chronically ill and disabled people may support our results.

Many studies have shown that caregiving affects physical, mental, emotional, and functional health of the caregiver $[1,33,34]$. It is possible that this effect will be greater in people who have had mental illness before. In this study, in accordance with the expectations, both the ZCBS and BSI scores of the companions who had a previous mental illness were significantly higher. Nearly three-quarters of their companions who had a history of mental illness reported that they suffered from depression. These companions had higher ZCBS and BSI scores.

The ZCBS and BSI scores of the companions who did not receive support and assistance from the other family members were significantly higher than those receiving support $(p<.05)$. In a study on the care burden of informal family caregivers providing home care, Yigitalp et al. [35] found that the care burden of caregivers receiving help and support from other family members decreased significantly. In a study by Otis-Green and Juarezet [36], it was found that social support had a significant effect on the quality of life of family caregivers. In a study by Ergh et al [37], it was revealed that as the severity of the patient's disease increases, the caregiver's anxiety also increases if they do not have the proper support. These findings show that the support of family members reduces the care burden and positively affects the health of the caregiver. For this reason, it is important that health professionals encourage the other family members to support caregiver to enhance the healing of the patients in both hospital and home. Health professionals need to monitor the health status of caregivers more carefully.

Care burden has a substantial effect on caregivers' health. Many studies showed that informal home caregivers have a high health risk for burden, stress, depression, irritability, and aggression, and these health problems were associated with a variety of health complications during caregiving [38, 39]. In a study conducted by Schulz and Beach [40], individuals who care for their spouses at an older age were compared in a 4-year cohort study. It was found that the mortality risk of individuals who care for their spouse and feel the burden of care is $63 \%$ higher than those who do not need to care for their spouse. 
In our study, $46.7 \%$ of the companions stated that they cared for their patients outside the hospital. These people have higher ZBI scores and BSI scores than companions just providing care in the hospital. These companions may also be considered home caregivers and may have the same health risks as home caregivers. Healthcare professionals need to monitor the health status of these people more carefully.

It is accepted that educating caregivers or companions about the illness and care process may reduce the anxiety and care burden of caregivers or companions, and may therefore have positive results in family relations $[1,8,41]$.

In our study, companions reported that they were pleased to have adequate explanations from physicians about the condition and care of their patients. Getting enough information from the physicians in the hospital and consulting them when making healthcare decisions reduces concerns about their patients' treatment and prognosis. For this reason, it is important for healthcare professionals to consider hospitalized patients and their companions in a more empathetic manner and to take medical decisions in a shared decision-making approach. This attitude will increase physicians' satisfaction by improving patient outcomes [42].

\section{Conclusion}

The companions of the hospitalized patients had a mean ZCBS score of 20.2 and a mean BSI score of 34.4. As the care burden of companions increased, the levels of psychological distress also increased. The support of health workers and family members reduced the companions' care burden and psychological distress. Companions also need more assistance from health care institutions to cope with the care burden. Physicians working in the hospital should take into account that companions may be hidden patients and should encourage other family members to provide support to the companions to protect their health.

Companions can increase the efficacy of healthcare services by facilitating communication between patients and healthcare providers. By providing physical and emotional support to the patient, the companion contributes to the patient's recovery and shortens the length of hospital stay [2]. In the last decades, the participation of family members in hospital care has been encouraged. In order for family members to make the best of their contribution to health care, their health should be protected, their care burden should be reduced, and support should be provided. It requires hospital administrators and ministry of health officials to work together and arrange appropriate and sufficient physical conditions (e.g., spaces for resting and sleeping) for companions within the hospital.

\section{The limitation of the Study and Suggestions for Future Studies}

This study is the first to investigate companions' health status and care burden. There are some limitations to our study. First, as a cross-sectional study from a single center, the findings of this study might be difficult to generalize, and no cause-effect relationship could be established because the sample was not clinically and demographically representative of the general population. Second, this study is based on the subjective assessments of companions. To the best of our knowledge, this is the first study investigating the health status of companions. Third, the companionship is not unique to Turkey as explained above. Multi-center studies with larger samples are needed on companions. Further studies are needed to increase the generalizability of this study's findings. 


\section{References}

[1] Collins L, Swartz K. Caregiver care. Am Fam Physician. 2011;83(11):1309-1317.

[2] McDaniel S, Campbell T, Hepworth J, Lorenz A. Acute hospital care: Letting the family in. family oriented primary care. 2nd ed. P. 414-431. Newyork. Springer Science and Business Media Inc; 2005.

[3] Faison KJ, Faria SH, Frank D, Caregivers of chronically ill elderly: perceived burden. Journal of Community Health Nursing. 1999;16(4):243-53.

[4] George LK, Gwyther LP, Caregiver well-being: a multidimensional examination of family caregivers of demented adults. The Gerontologist. 1986;26:253-259

[5] Zarit SH. Todd PA, Zarit JM. Subjective burden of husbands and wives as caregivers: a longitudinal study. Gerontologist. 1986;26(3):260-266.

[6] Atagün MI, Balaban OD, Atagün Z, Elagoz M, Ozpolat AY. caregiver burden in chronic diseases, current approaches in psychiatry. 2013;3:513-552.

[7] Adelman RD, Timanova LL, Delgado D, Dion S, Lachs MS. Caregiver burden: A clinical review. Journal of the American Medical Association. 2014;311(10):1052-1059.

[8] Goldberg A, Rickler KS. The role of family caregivers for people with chronic illness. Rhode Island Medical Journal. 2011;94(2):41-42.

[9] Akpinar A, Ozcan M, Toygar DU. Patient's companions as a vulnerable group in Turkish hospitals: A descriptive study. J Eval Clin Pract. 2020;26:1196-1204.

[10] Miller AD, Mishra SR, Kendall L, Haldar S, Pollack AH, Pratt W. Partners in care: design considerations for caregivers and patients during a hospital stay. CSCW. 2016;2016:756-769.

[11] Popli UK, Panday R. caregivers burden of hospitalized elderly. J Gerontol Geriatr Res. 2018;7:483.

[12] Passos SSS, Pereira A, Nitschke RG. Routine of the family companion during hospitalization of a family member. Acta Paul Enferm. 2015;28(6):539-45.

[13] Stavrianou A, Kafkia T, Mantoudi A, Minasidou E, Konstantinidou A, Sapountzi-Krepia D, Dimitriadou A. Informal caregivers in Greek hospitals: a unique phenomenon of a health system in financial crisis. Mater Sociomed. 2018;30(2):147-152.

[14] Bellou-Milona P, Iordanou P, Kyriakidou H, Andrea S, Evangelou H, Kostandou H. Family members involvement in their hospitalized patients care. ICUs and Nursing Web Journal. 2002;12:1-10.

[15] Lavdaniti M, Raftopoulos V, Sgantzos M, Psychogiou M, Areti T, Georgiadou C, Serpanou I, Sapountzi-Krepia D. Inhospital informal caregivers' needs as perceived by themselves and by the nursing staff in Northern Greece: A descriptive study. BMC Nursing. 2011;10(1):19.

[16] Sapountzi-Krepia D, Raftopoulos V, Sgantzos M, Dimitriadou A, Ntourou I, Sapkas G. Informal in-hospital care in a rehabilitation setting in Greece: An estimation of the nursing staff required for substituting this care. Disability and Rehabilitation. 2006;28(1):3-11.

[17] Sapountzi-Krepia D, Raftopoulos V, Psychogiou M, Sakellari E, Toris A, Vrettos A, Arsenos P. Dimensions of informal care in Greece: the family's contribution to the care of patients hospitalized in an oncology hospital. Journal of Clinical Nursing. 2008;17(10):1287-1294.

[18] Rotman-Pikielny P, Rabin B, Amoyal S, Mushkat Y, Zissin R, Levy Y. Participation of family members in ward rounds: attitude of medical staff, patients and relatives. Patient Education And Counseling. 2007;65(2):166-170.

[19] Islam MS, Luby SP, Sultana R, Rimi NA, Zaman RU, Uddin M, Nahar N et al. Family caregivers in public tertiary care hospitals in Bangladesh: risks and opportunities for infection control. American Journal of Infection Control. 2014;42(3):305-310.

[20] Sadigh M, Nawagi F, Sadigh M. The economic and social impact of informal caregivers at Mulago National Referral Hospital, Kampala, Uganda. Annals of Global Health. 2016;82(5):866-874.

[21] Saritas SC, Kavak F, Aksoy A, Saritas S. Examination of the care burden of caregivers of oncology patients and the perceived social support from family. International Journal of Caring Sciences. 2017;10(1):447-455

[22] Celik Y, Hikmet N, Santas F, Aksungur A, Topaktas G, Turac IS. Patient companions in the Turkish healthcare system: the role, expectations and problems. Health and Social Care in the Community. 2017;25(3):1199-1208.

[23] Inci HF, Erdem ME. Adaptation, validity and reliability of caregiving burden scale into Turkish [master's thesis]. Pamukkale University Institute of Health Sciences. Denizli. Turkey; 2006.

[24] Derogatis LR, Melisaratos N. The brief symptom inventory: An introductory report. Psychological Medicine. 1983;13:595-605. 
[25] Sahin N, Durak A. The brief symptom inventory, adaptation for Turkish youth. Turkish Journal of Psychology. 1994;9(31):44-56.

[26] Ruiz IJ, Nicolas MM. The family caregiver: the naturalized sense of obligation in women to be caregivers. Enfermeria Global. 2018;49:434-447.

[27] Family Caregiver Alliance (FCA). Caregiver Statistics: Demographics. 2020. Available from: https://www.caregiver.org/caregiver-statistics-demographics.

[28] Chandran S, Kishor M, Mathur S, Mathusudhan BN, Kavya N. Caregiver Burden and self-efficacy: A hospital-based comparison between general and special ward patients. Journal of Medical Sciences and Health. 2019;5(1):27-34.

[29] Rodríguez-González AM, Rodríguez-Míguez E. A metaanalysis of the association between caregiver burden and the dependent's illness. Journal of Women \& Aging. 2020;32(2):220-235.

[30] Sakarya S. Epidemiology of multimorbidity in primary care in the context of chronic diseases. Clinics Turkey. 2019:6-11.

[31] Jones DA, Peters TJ. Caring for elderly dependants: effects on the carers' quality of life. Age and Ageing. 1992;21(6):4218.

[32] Ohrnberger J, Fichera E, Sutton M. The relationship between physical and mental health: A mediation analysis. Social Science \& Medicine. 2017;195:42-49.

[33] Oksuz E, Barış N, Arslan F, Ateş MA. Determine burden care for caregivers of cancer patients receiving chemotherapy. Anatolian Journal of Clinical Investigation. 2013;7(1):24-30.

[34] Qadeer A, Khalid U, Amin M, Murtaza S, Khaliq MF, Shoaib M. Caregiver's burden of the patients with traumatic brain injury. Cureus. 2017;9(8):e1590.

[35] Yigitalp G, Surucu HA, Gumus F, Evinc E. Predictors of caregiver burden in primary caregivers of chronic patients. International Journal of Caring Sciences. 2017;10(3):1168-77.

[36] Otis-Green S, Juarez G. Enhancing the social well-being of family caregivers. Semin Oncol Nurs. 2012;28(4):246-55.

[37] Ergh TC, Rapport LJ, Coleman RD, Hanks RA. Predictors of caregiver and family functioning following traumatic brain injury: Social support moderates caregiver distress. The Journal of Head Trauma Rehabilitation. 2002;17(2):155-74.

[38] Rezaei H, Niksima SH, Gheshlagh RG. Burden of Care in Caregivers of Iranian patients with chronic disorders: a systematic review and meta-analysis. Health and Quality of Life Outcomes. 2020;18:261-271.

[39] Roth DL, Fredman L, Haley WE. Informal caregiving and its impact on health: a reappraisal from population-based studies. The Gerontologist. 2015;55(2):309-319.

[40] Schulz R, Beach SR. Caregiving as a risk factor for mortality: the Caregiver. Health Effects Study. JAMA. 1999;282(23):2215-9.

[41] Lim JW, Zebrack B. Caring for family members with chronic physical illness: a critical review of caregiver literature. Health and Quality of Life Outcomes. 2004;2(1):50.

[42] National Institute for Health and Care Excellence. Shared decision making, Key terapeutic topic 2019. Available from: www.nice.org.uk/guidance/ktt23

\section{Declarations}

\section{Ethics approval and consent to participate}

The scientific and ethical relevance of this study was approved by the Akdeniz University Faculty of Medicine Clinical Research Ethics Committee dated 20 December 2017 and numbered 747. All researchers have signed the declaration of Helsinki. Written consent was obtained from all participants. Written informed consent was obtained from all companions who agreed to participate in the study.

\section{Acknowledgements}

Not applicable.

\section{Disclosure Statement}

No potential conflict of interest was reported by the authors.

\section{Funding Acknowledgements}

Not applicable. 